\title{
Living with an imperfect cell wall: compensation of femAB inactivation in Staphylococcus aureus Judith Hübscher ${ }^{1}$, Andrea Jansen ${ }^{2}$, Oliver Kotte ${ }^{3}$, Juliane Schäfer ${ }^{4}$, Paul A Majcherczyk ${ }^{5}$, Llinos G Harris 6,7 , Gabriele Bierbaum², Matthias Heinemann ${ }^{3}$ and Brigitte Berger-Bächi*1
}

\author{
Address: ${ }^{1}$ Institute of Medical Microbiology, University of Zürich, Zürich, Switzerland, ${ }^{2}$ Institute for Medical Microbiology, Immunology and \\ Parasitology, University of Bonn, Bonn, Germany, ${ }^{3}$ Institute of Molecular Systems Biology, ETH Zürich, Zürich, Switzerland, ${ }^{4}$ Seminar for \\ Statistics, ETH Zürich, Zürich, Switzerland, ${ }^{5}$ Division of Infectious Diseases, Department of Internal Medicine, Centre Hospitalier Universitaire \\ Vaudois, Lausanne, Switzerland, ${ }^{6} \mathrm{AO}$ Research Institute, Davos, Switzerland and ${ }^{7}$ School of Medicine, University of Wales Swansea, Swansea, UK \\ Email: Judith Hübscher - jhuebsch@immv.uzh.ch; Andrea Jansen - Andrea.Jansen@mibi03.meb.uni-bonn.de; \\ Oliver Kotte - kotte@imsb.biol.ethz.ch; Juliane Schäfer - schaefer@stat.math.ethz.ch; Paul A Majcherczyk - Paul.Majcherczyk@unil.ch; \\ Llinos G Harris - L.G.Harris@swansea.ac.uk; Gabriele Bierbaum - bierbaum@mibi03.meb.uni-bonn.de; \\ Matthias Heinemann - heinemann@imsb.biol.ethz.ch; Brigitte Berger-Bächi* - bberger@immv.uzh.ch \\ * Corresponding author
}

Published: 4 September 2007

BMC Genomics 2007, 8:307 doi:10.1186/147/-2164-8-307

This article is available from: http://www.biomedcentral.com/147I-2/64/8/307

(C) 2007 Hübscher et al; licensee BioMed Central Ltd.

This is an Open Access article distributed under the terms of the Creative Commons Attribution License (http://creativecommons.org/licenses/by/2.0), which permits unrestricted use, distribution, and reproduction in any medium, provided the original work is properly cited.
Received: 26 February 2007

Accepted: 4 September 2007

\begin{abstract}
Background: Synthesis of the Staphylococcus aureus peptidoglycan pentaglycine interpeptide bridge is catalyzed by the nonribosomal peptidyl transferases FemX, FemA and FemB. Inactivation of the femAB operon reduces the interpeptide to a monoglycine, leading to a poorly crosslinked peptidoglycan. fem $A B$ mutants show a reduced growth rate and are hypersusceptible to virtually all antibiotics, including methicillin, making FemAB a potential target to restore $\beta$-lactam susceptibility in methicillin-resistant $S$. aureus (MRSA). Cis-complementation with wild type femAB only restores synthesis of the pentaglycine interpeptide and methicillin resistance, but the growth rate remains low. This study characterizes the adaptations that ensured survival of the cells after femAB inactivation.
\end{abstract}

Results: In addition to slow growth, the cis-complemented femAB mutant showed temperature sensitivity and a higher methicillin resistance than the wild type. Transcriptional profiling paired with reporter metabolite analysis revealed multiple changes in the global transcriptome. A number of transporters for sugars, glycerol, and glycine betaine, some of which could serve as osmoprotectants, were upregulated. Striking differences were found in the transcription of several genes involved in nitrogen metabolism and the arginine-deiminase pathway, an alternative for ATP production. In addition, microarray data indicated enhanced expression of virulence factors that correlated with premature expression of the global regulators sae, sarA, and agr.

Conclusion: Survival under conditions preventing normal cell wall formation triggered complex adaptations that incurred a fitness cost, showing the remarkable flexibility of $S$. aureus to circumvent cell wall damage. Potential FemAB inhibitors would have to be used in combination with other antibiotics to prevent selection of resistant survivors. 


\section{Background}

The peptidoglycan structure of Staphylococcus aureus is a dynamic, three-dimensional meshwork consisting of multiple layers of glycan strands that are crosslinked through peptide bridges. It determines the bacterial shape and confers protection against the high internal turgor. Characteristic for the staphylococcal peptidoglycan is the long and flexible pentaglycine interpeptide, which branches off the $\varepsilon$-amino group of the L-lysine of the peptidoglycan stem peptide. The pentaglycine interpeptide is synthesized in a sequential fashion by the FemABX family of nonribosomal peptidyl transferases, which use glycyltRNA as a glycine donor. While FemX (synonym: FmhB) adds the first glycine, FemA and FemB add Gly $_{2,3}$ and Gly $_{4,5}$, respectively [1-4]. Although structurally and functionally related, these factors cannot substitute for one another [5]. Growth of mutants with a shortened interpeptide is strongly impaired [2]. They display a massive reduction in cell wall crosslinking, aberrant septum formation, and hypersusceptibility to antibiotics including all $\beta$-lactams $[1,2]$. In methicillin-resistant $S$. aureus (MRSA), methicillin resistance is completely abolished upon inactivation of $f e m A$, suggesting that the monoglycine peptidoglycan is a very poor substrate for the native penicillin-binding proteins (PBPs) as well as for the low affinity PBP2a encoded by mecA, which confers resistance to $\beta$-lactams. FemX and/or FemA were therefore regarded as potential targets for novel antibacterial agents, which could restore $\beta$-lactam susceptibility in MRSA [6]. While FemX was shown to be essential [7], fem $A B$ null mutants were postulated to require a secondary, yet uncharacterized compensatory or suppressor mutation(s) $c h r^{*}$ to stabilize the cell [6]. The phenotype of a fem $A B$ null mutant thus reflects not only the consequences of the inactivation of the fem $A B$ operon, but additionally the effects due to the postulated compensatory mutation(s). These compensatory events or adaptations are of potential interest, as they may tell us about the interrelationship between cell wall synthesis and other cellular mechanisms. By reintroducing the $f e m A B$ wild type allele in cis, the compensatory effects were separated from those due to the fem $A B$ inactivation. This allowed us to study the consequences of the adaptation events in the presence of a restored pentaglycine interpeptide synthesis machinery.

\section{Results and discussion}

Phenotypic characterization of the femAB+ backcross

The femAB null mutant AS145 derived from the MRSA BB270 produces only a monoglycine peptidoglycan interpeptide and shows a poorly crosslinked peptidoglycan, aberrant septum formation, methicillin hypersusceptibility, and a reduced growth rate [2]. Back-transduction of the wild type $f e m A B$ allele in cis by selecting for the upstream, co-transducible, silent insertion

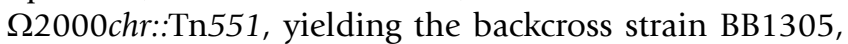
restored methicillin resistance, but did not increase the growth rate [6]. Therefore, survival of AS145 was suggested to require a postulated compensatory mutation termed $c h r^{*}$, which was retained in BB1305. The MRSA strain BB903, which was obtained by transduction of

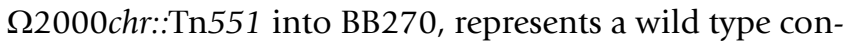
trol strain isogenic to BB1305 except for the postulated chr* mutation (Table 1).

Compared to the highly enlarged cells of AS145, cells of strain BB1305, which were again able to produce a pentaglycine interpeptide, regained the same size as those of the wild type strain BB903 (Figure 1A), suggesting a regular cell separation. The muropeptide pattern of AS145 showed a highly increased amount of uncrosslinked monomeric muropeptides at the cost of the oligomeric peaks as described earlier [2]. The wild type muropeptide profile was then re-established in BB1305 as the characteristic peaks of the dimeric, trimeric, and oligomeric muropeptide fractions were indistinguishable from those of BB903 (Figure 1B). However, calculation of the percentage of free reducing termini in the peptidoglycan revealed on average slightly longer glycan chains in AS145 and BB1305 than in BB903 (Figure 2) as confirmed by two-sided $t$-test, suggesting that AS145 may have compensated for the poorly crosslinked cell wall by generating longer sugar chains.

In addition to the reduced growth rate, which may be a further strategy to cope with the cell wall defects caused by

Table I: S. aureus strains used in this study

\begin{tabular}{|c|c|c|c|c|}
\hline \multirow[t]{2}{*}{ Strain } & \multirow[t]{2}{*}{ Relevant genotype and phenotype ${ }^{a}$} & \multicolumn{2}{|c|}{ Specific growth rate ${ }^{b}[\mathrm{I} / \mathrm{h}]$} & \multirow[t]{2}{*}{ Source or reference } \\
\hline & & $37^{\circ} \mathrm{C}$ & $42^{\circ} \mathrm{C}$ & \\
\hline BB270 & NCTC8325 background, SCCmec type I; Mc-r, lysostaphin-s & nd & nd & [72] \\
\hline BB903 & BB270, $\Omega 2000$ chr::Tn55 I; Mc-r, Em-r, lysostaphin-s & 1.38 & 1.36 & This study \\
\hline ASI 45 & BB270, femAB::tetK, chr*; Mc-s, lysostaphin-r & 0.94 & 0.78 & [2] \\
\hline BBI305 & $\begin{array}{l}\text { ASI } 45, \Omega 2000 \text { chr::Tn55I (femAB+), chr*; Mc-r, Em-r, } \\
\text { lysostaphin-s }\end{array}$ & 1.09 & 0.85 & [6] \\
\hline
\end{tabular}

aMc, methicillin; Em, erythromycin; r, resistant; s, susceptible.

bGrowth in LB broth. nd, not determined. 
A

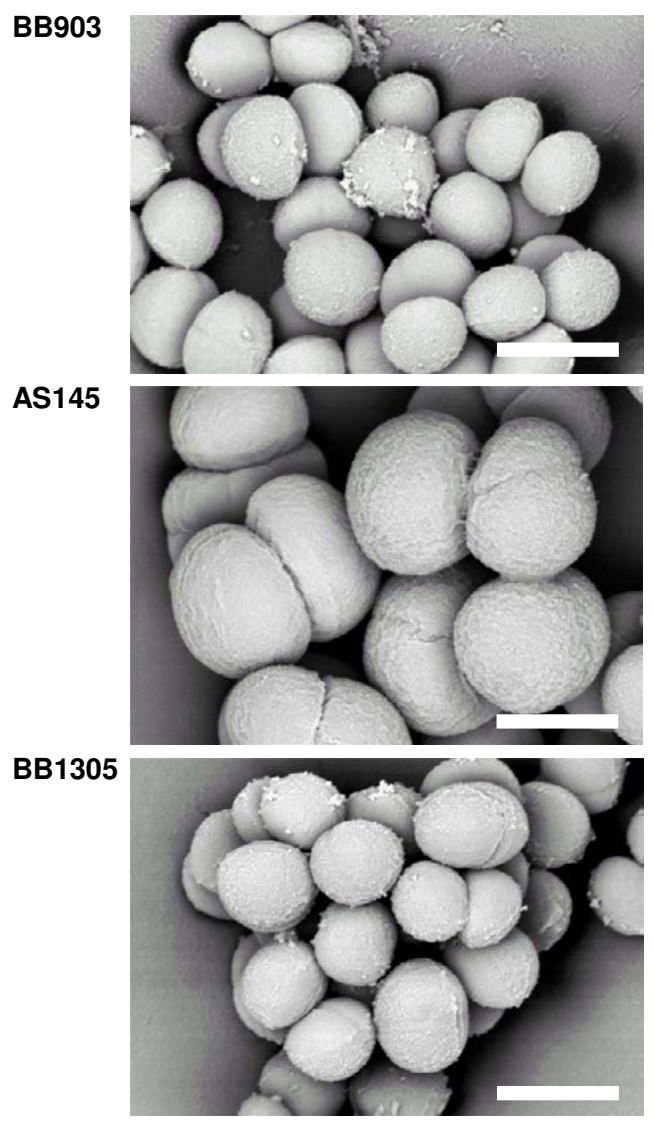

B

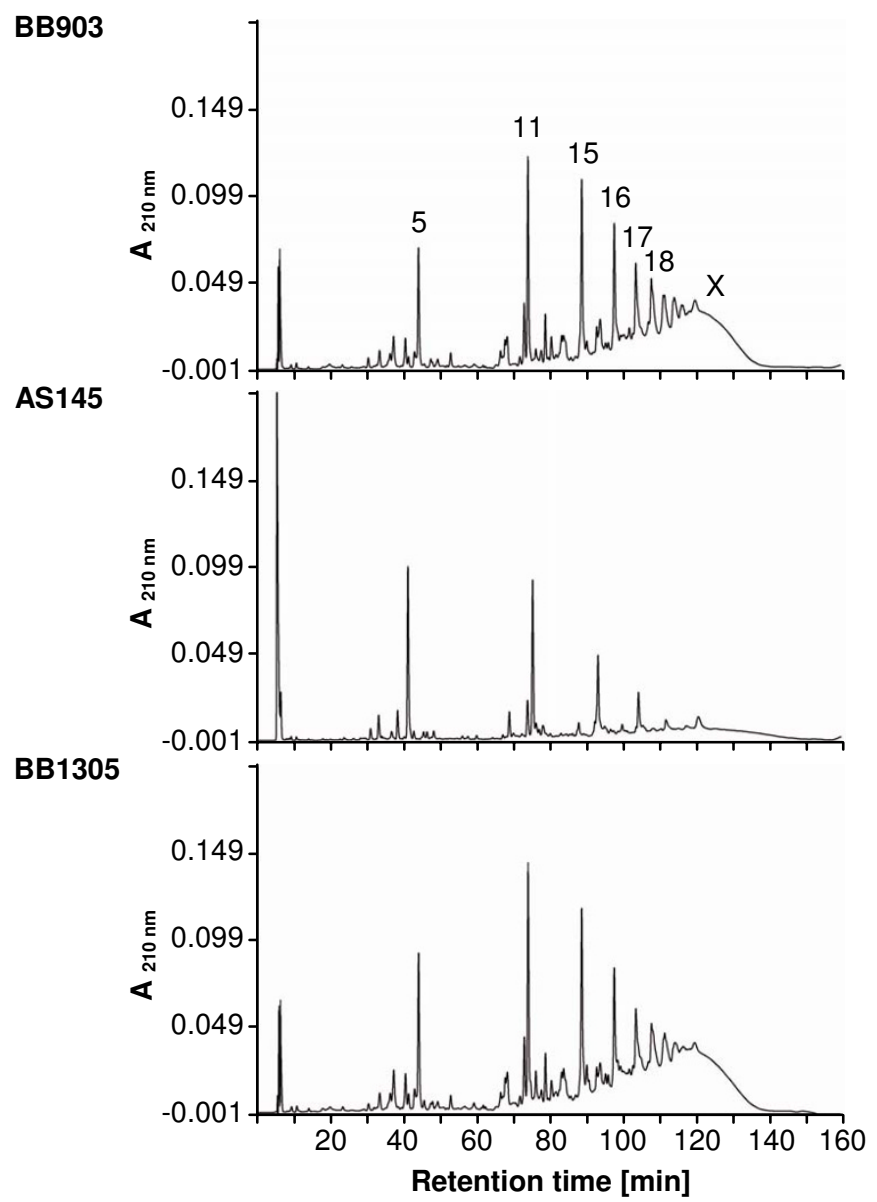

Figure I

(A) Scanning electron microscopy pictures of cells adhering to Thermanox. The cells of the femAB null mutant ASI45 are highly enlarged, while the femAB+ backcross BBI 305 and the wild type BB903 show cells of the same size and appearance. The white bar corresponds to I $\mu \mathrm{m}$. (B) Muropeptide pattern. The corresponding cell walls were digested with muramidase and subjected to reversed-phase HPLC. Major muropeptide components are numbered according to de Jonge [56]. Strains BB903 and BBI305 show a muropeptide profile characteristic of wild type $S$. aureus strains, with the highest peak in the dimeric fraction (peaks II and I2) and a high degree of crosslinking (peaks I5 and higher), while ASI45 has the highest peak in the monomeric fraction (peaks I to 5) and a reduced amount of oligomeric muropeptides [2].

the femAB deletion, we found that AS145 and BB1305 also shared temperature sensitivity (Figure 3 ). The autolytic banding patterns and spontaneous and Triton X-100induced autolysis, at both 37 and $42{ }^{\circ} \mathrm{C}$, were virtually identical in the slowly growing fem $A B+$ backcross BB1305 and the wild type BB903 (data not shown), suggesting that there was no correlation between the autolytic behaviour of BB1305 and the reduced growth rates observed. Although the overall autolysis did not differ, subtle modulation in autolytic activities may count for the slightly increased glycan chain length.
The strains used in this study all carry a functional mecA gene and thus are MRSA. A characteristic feature of MRSA strains is the heterogeneous expression of resistance to methicillin and other penicillinase-stable $\beta$-lactams such as oxacillin, whereby the majority of cells have only a low resistance level. Upon exposure to inhibitory concentrations of $\beta$-lactams, a subpopulation with high resistance is selected. Once formed, high resistance is maintained in absence of selective pressure resulting in MRSA with homogeneous oxacillin resistance. Interestingly, detailed analyses showed that the oxacillin resistance of the fem $A B+$ backcross BB1305 had become higher than that of 


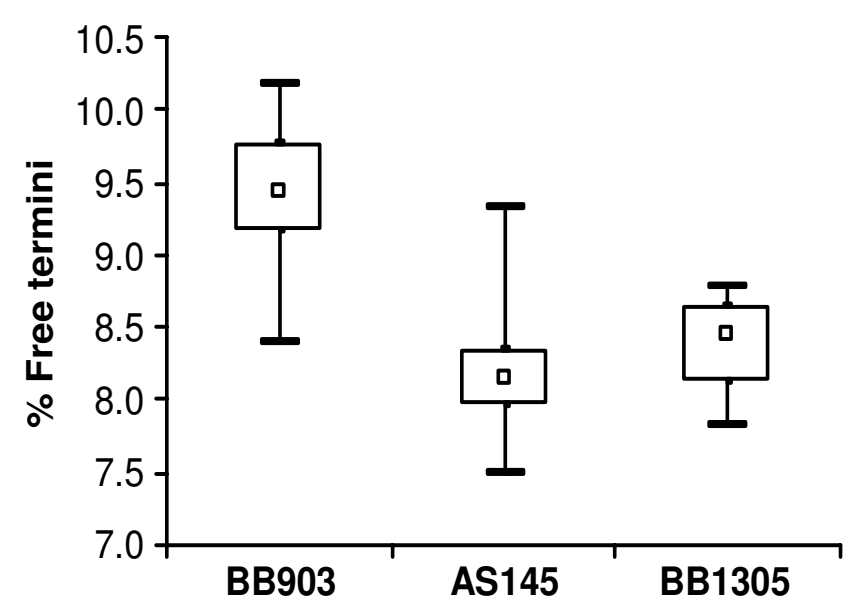

\section{Figure 2}

Glycan chain length. The box and whiskers diagram illustrates variations in the percentage of free reducing termini in the peptidoglycan, which are a measure of the glycan chain length. Lower values such as obtained with the femAB null mutant ASI45 and its femAB+ derivative BBI305 indicate an elongated glycan chain. The square marks the median of six measurements, the lower and upper border of the box is given by the first and the third quartile, respectively. The minimum and maximum values obtained are shown by horizontal bars.

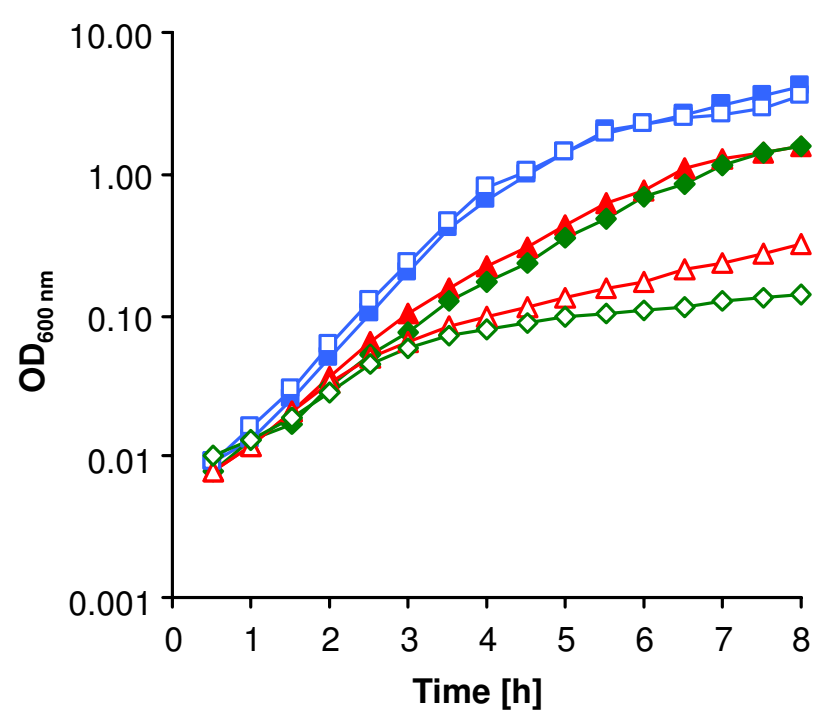

Figure 3

Temperature dependence of growth. Growth curves of the femAB null mutant ASI 45 (green diamonds), the femAB+ backcross BBI 305 (red triangles), and the wild type BB903 (blue squares). The specific growth rates are indicated in Table I. Closed symbols, growth at $37^{\circ} \mathrm{C}$; open symbols, growth at $42^{\circ} \mathrm{C}$. the parental strain $\mathrm{BB} 270$ and of $\mathrm{BB} 903$, as shown in the population analysis profiles (Figure $4 \mathrm{~A}$ ) and by growth on an oxacillin gradient plate (Figure 4B). Oxacillin resistance was thus overcompensated in BB1305 and resembled homogeneous resistance as if selected by passage on inhibitory concentrations of oxacillin. In contrast, BB1305 remained hypersusceptible to teicoplanin and bacitracin (Figure 4B). The increased susceptibility to teicoplanin, which interestingly did not extend to vancomycin (data not shown), may indicate changes in the cell membrane with which the lipophilic anchor of teicoplanin interacts [8]. It is therefore likely that the bacitracin and teicoplanin hypersusceptibility of BB1305 and AS145 point to changes in the envelope and membrane organisation.

\section{Transcriptome analysis}

Given the multiple phenotypic traits that were not complemented by restoring the pentaglycine interpeptide, changes in the genome transcription profile were expected. In a snapshot of the transcriptomes of exponentially growing cells by microarray analysis, 56 genes were reported to be downregulated in the fem $A B+$ backcross strain BB1305 compared to the wild type strain BB903, and 81 genes were reported to be upregulated [see Additional file 1]. The list of differentially expressed genes was determined using the moderated $t$-statistics [9], followed by the family-wise error rate (FWER)-based $p$-value adjustment according to Holm [10], in order to guarantee high confidence in the selected genes.

The distribution of functional classes within the downand the upregulated genes (Table 2) is depicted in pie charts for comparison with their occurrence within the total of genes represented on the chip (Figure 5). Among the downregulated genes in the mutant, categories significantly overrepresented as determined by Fisher's exact test comprised transport/binding proteins and lipoproteins, protein synthesis, metabolism of lipids, nucleotides and nucleic acids. Taking into account the decreased growth rate of BB1305, this finding may in part reflect the differences in growth between the two strains tested, particularly with regard to protein synthesis. In contrast, the categories that were overrepresented among the upregulated genes, i.e. metabolism of amino acids and carbohydrates, pathogenic factors, and phage-related functions, may point to changes in metabolism selected by an overall stress response to the original $f e m A B$ deletion.

\section{Metabolic differences}

To uncover metabolic differences between the two strains, we made use of recent systems biology advances: In contrast to an otherwise isolated analysis of single genes, we computationally linked the transcriptional data with a recently developed metabolic network model for $S$. aureus 
A

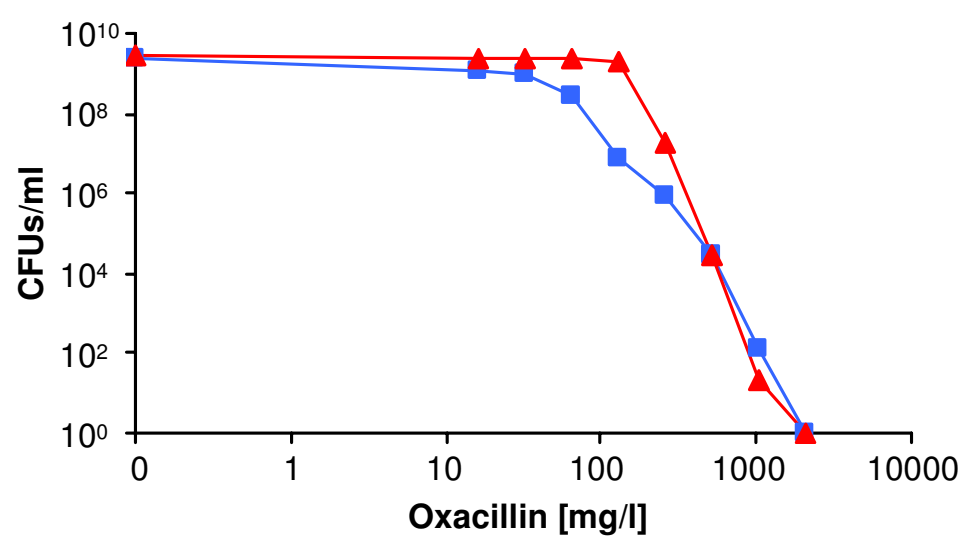

B

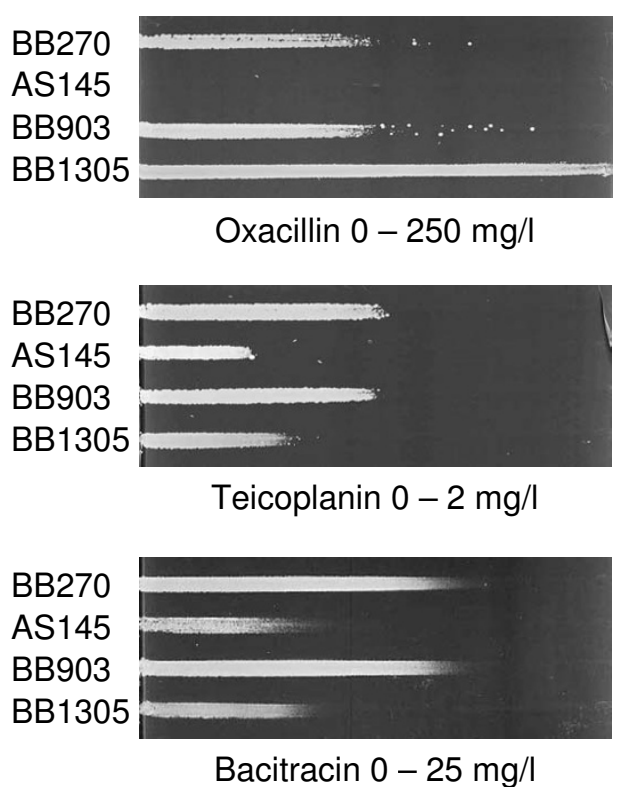

Figure 4

Changes in antibiotic resistance. (A) Population analysis resistance profiles of the femAB+ backcross BBI 305 (red triangles) compared to the corresponding wild type MRSA BB903 (blue squares). (B) Antibiotic gradient plates visualizing differences in resistance levels between the femAB null mutant $A S I 45$, the femAB+ backcross BBI305, and the two MRSA strains $B B 270$ and BB903.

[11] (see Methods). This procedure allowed us to consider the transcriptional differences between the two strains in a metabolic context. The mapping of transcriptional data onto a metabolic network, which underlies the employed computational algorithm, allows to identify spots (socalled reporter metabolites) around which significant regulation occurs, and thus assists in carving out metabolism-related insight from the microarray data. The top scoring reporter metabolites with $p$-values smaller than 0.05 are listed in Table 3 and an overview of pathways in which many of these reporter metabolites occur is given in Figure 6.

The arginine-deiminase pathway was found to be upregulated in BB1305. This pathway imports extracellular arginine driven by the simultaneous excretion of ornithine via the arginine-ornithine antiporter $\mathrm{ArcD}$ (SA2426). Arginine is then converted by the argininedeiminase (ArcA) to citrulline, which is further metabolized by the ornithine transcarbamoylase (ArcB) to ornithine and carbamoyl phosphate. The carbamate kinase (ArcC) finally breaks down the latter into ammonia and carbon dioxide yielding one ATP. This pathway is perceived to act as an ATP source under anaerobic conditions and in small colony variants (SCV) lacking a functional respiratory chain $[12,13]$, and it is also thought to be an important player in $\mathrm{pH}$ homeostasis as it was also found to be expressed in biofilms [14-16]. Furthermore, depletion of arginine by the arginine-deiminase pathway, which inhibits nitric oxide production in the host, and thus both the innate and the adaptive immune responses against microbial infections, may increase staphylococcal virulence [17].

Another observation was a reduction in $g \ln A$ expression in the fem $A B+$ backcross BB1305, as was confirmed by Northern blots of the glnRA operon (data not shown). The glutamine synthetase (GS) GlnA produces L-glutamine from L-glutamate and ammonia using one ATP to drive the reaction. Glutamine plays a central role in nitrogen metabolism and functions as an amino group donor in many biosynthetic pathways, leading to the synthesis of histidine, tryptophan, carbamoyl phosphate, glucosamine-6-phosphate, purines, and pyrimidines. A mutation in $g \ln R$, which has a polar effect on $g \ln A$, results in a decreased GS activity and in a reduction of the amidation of the iD-glutamate of the peptidoglycan stem peptide thereby reducing methicillin resistance [18]. $g \ln A$ downregulation in BB1305 may reflect an overall reduced requirement for nitrogen due to slowed down growth. 
Table 2: Functional classification and numbers of genes that were found differentially expressed in the femAB+ backcross BB 1305 compared to the corresponding wild type BB 903 as determined by microarray analysis

\begin{tabular}{|c|c|c|c|c|c|}
\hline \multirow[t]{2}{*}{ Function $^{\mathrm{a}}$} & \multicolumn{3}{|c|}{ Number of ORFs } & \multicolumn{2}{|c|}{ Overrepresentation ${ }^{b}$} \\
\hline & Chip & Down & Up & & $p$-value \\
\hline Cell wall & 63 & 2 & 0 & & \\
\hline $\begin{array}{l}\text { Membrane bioenergetics (electron transport chain and ATP } \\
\text { synthase) }\end{array}$ & 58 & 1 & 2 & & \\
\hline Transport/binding proteins and lipoproteins & 254 & 16 & II & down & $<0.001$ \\
\hline Protein secretion & 12 & 0 & 0 & & \\
\hline Sensors (signal transduction) & 19 & 0 & 0 & & \\
\hline $\begin{array}{l}\text { Cell division, germination, sporulation, and transformation/ } \\
\text { competence }\end{array}$ & 34 & 0 & 0 & & \\
\hline $\begin{array}{l}\text { DNA modification, repair, recombination, replication, packaging, } \\
\text { and segregation }\end{array}$ & 80 & 0 & 3 & & \\
\hline Protein folding and modification & 35 & 1 & I & & \\
\hline Protein synthesis & 85 & 6 & 0 & down & 0.015 \\
\hline RNA modification & 20 & 0 & 0 & & \\
\hline RNA synthesis & 132 & 3 & 8 & & \\
\hline Metabolism of lipids & 50 & 4 & 3 & down & 0.030 \\
\hline Metabolism of amino acids and related molecules & 143 & 7 & 10 & up & 0.029 \\
\hline Metabolism of carbohydrates and related molecules & 134 & 2 & 10 & up & 0.023 \\
\hline Metabolism of coenzymes and prosthetic groups & 70 & 0 & 1 & & \\
\hline Metabolism of nucleotides and nucleic acids & 74 & 5 & 3 & down & 0.030 \\
\hline Metabolism of phosphate and sulfur & 8 & 0 & 0 & & \\
\hline Adaptation to atypical conditions & 44 & 0 & I & & \\
\hline Pathogenic factors (toxins and colonization factors) & 97 & $\mathbf{I}$ & 9 & up & 0.006 \\
\hline Phage-related functions & 43 & 0 & 7 & up & 0.001 \\
\hline Detoxification, transposon and IS, miscellaneous & 66 & 1 & 2 & & \\
\hline Similar to unknown proteins, no similarity & 811 & 7 & 10 & & \\
\hline Total ORFs & 2332 & 56 & 81 & & \\
\hline
\end{tabular}

aThe cellular main roles are in accordance with the annotation on the DOGAN website [73].

bOverrepresented functions either among the down- or the upregulated genes are printed in bold and the respective $p$-values as determined by Fisher's exact test are given.

Interestingly, another link to nitrogen metabolism was found in the increased amounts of ureB (urease beta subunit) and ureF (urease accessory protein UreF) transcripts displayed by strain BB1305, which was consistent with the derepression of urease production observed in AS145 and BB1305 in urea-containing medium (Figure 7). On the one hand the urease reaction supplies nitrogen and on the other hand it serves the maintenance of the $\mathrm{pH}$ value by formation of ammonium. Urease expression is induced during nitrogen-limited growth $[19,20]$, and upregulation is observed in glnA mutants [20], growth in biofilms [14,15], and under heat shock conditions [21].

A downregulation of numerous members of the pyrimidine operon comprising pyr $A B$, pyrB, pyrC, and pyrE as well as of the regulator $p y r R$ was detected in BB1305. The products of the pyr operon are involved in the de novo synthesis of pyrimidine nucleotides from bicarbonate and from intermediates of the central carbon metabolism or via salvage of preformed pyrimidine bases and nucleotides present in the medium. Transcription of the pyr operon was verified by dot blot analysis because of the large transcript expected, using a pyrP-specific probe (data not shown). A downregulation of the pyr operon was confirmed in early logarithmic growth phase at an optical density at $600 \mathrm{~nm}\left(\mathrm{OD}_{600}\right)$ of 0.4 , however, at an $\mathrm{OD}_{600}$ of 1, pyr mRNA levels in BB1305 were the same or even higher than in BB903 (data not shown). In Bacillus subtilis, PyrR controls the expression of the pyr operon by binding to specific sequences of the pyr mRNA thereby leading to attenuation of transcription $[22,23]$ in response to exogenous uracil and to intracellular UMP/phosphoribosyl pyrophosphate pools $[23,24]$. Richardson et al. noted that the pyr operon is repressed in response to nitrosative stress in S. aureus [25]. The upregulation of the arginine-deiminase pathway and the urease reaction as well as the downregulation of the glutamine synthesis may point to a potential action of nitrogen regulators on the pyr operon. Control of pyrR may be exerted by GlnR and TnrA [26-28], since a GlnR/TnrA consensus sequence [27,29-31] with two mismatches was identified 56 to $38 \mathrm{bp}$ upstream of the coding region of $p y r R$ in the public staphylococcal 
A

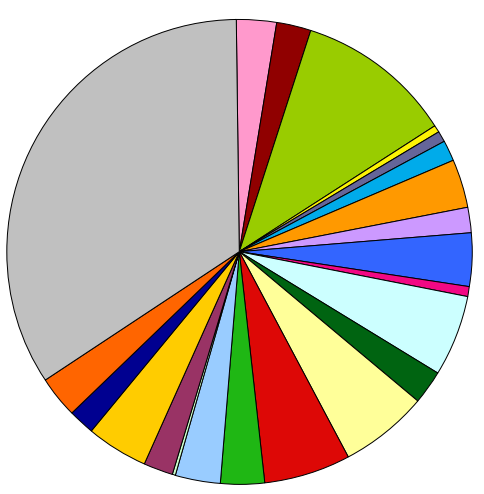

B

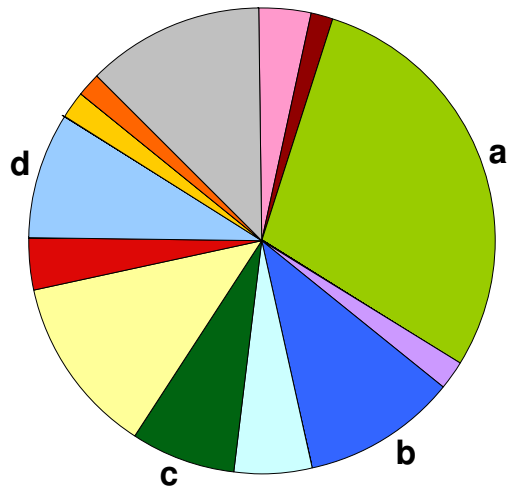

C

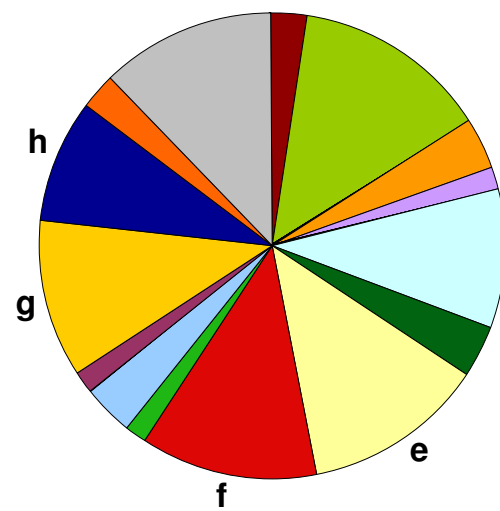

Cell wall

Membrane bioenergetics

Transport/binding proteins and lipoproteins

Protein secretion

Sensors (signal transduction)

$\square$ Cell envelope other 1)

$\square$ DNA-related functions 2)

Protein folding and modification

Protein synthesis

RNA modification

RNA synthesis
Metabolism of lipids

Metabolism of amino acids

- Metabolism of carbohydrates

Metabolism of coenzymes and prosthetic groups

Metabolism of nucleotides

Metabolism of phosphate and sulfur

Adaption to atypical conditions

Pathogenic factors

- Phage-related functions

Miscellaneous 3)

Similar to unknow proteins, no similarity

\section{Figure 5}

Pie charts of genes clustered according to their cellular functions. (A) All genes present on the microarray. (B) Genes detected to be downregulated in the femAB+ backcross BBI305. Overrepresented categories as determined by Fisher's exact test comprised transport/binding proteins and lipoproteins (a), protein synthesis (b), metabolism of lipids (c), and metabolism of nucleotides (d). (C) Upregulated genes in BBI305 with statistically overrepresented categories included metabolism of amino acids (e), metabolism of carbohydrates ( $f$ ), pathogenic factors (g), and phage-related functions (h). I) Cell envelope other comprises cell division, germination, sporulation, and transformation/competence; 2) DNA-related functions comprise DNA modification, repair, recombination, replication, packaging, and segregation; 3) Miscellaneous comprises also detoxification, transposon and IS.

genomes. While according to the microarray data a reduced transcription of pyrR was expected, signals obtained in Northern blots using a pyrR-specific probe were stronger in BB1305 than in BB903 (data not shown). These were the only discrepancies between microarray data and Northern blots found in the open reading frames tested, leaving the regulation of the pyrimidine operon and the link to the regulation of nitrogen-related functions open.

\section{Cell wall}

Although the fem $A B+$ backcross strain BB1305 produced on average slightly longer glycan chains, the transcription of $p b p B$, coding for the bifunctional PBP2 with transglyco- sylase activity [32], was not detected to be upregulated, as could have been expected, but downregulated. Furthermore, expression of the soluble glycosyltransferase genes, $s g t A$ and $s g t B[33,34]$ and of genes coding for glucosaminidases, which may contribute to an increased glycan chain length, could not be detected to be altered. These findings do not rule out a posttranscriptional control of autolytic activities by proteases $[35,36]$, since three genes encoding proteases (i.e. the cysteine protease $S \mathrm{spB}$, the zinc metalloproteinase aureolysin Aur, and the serine protease-like SplB) were significantly upregulated. In addition, the decreased expression of dltA, dltB, and dltD in BB1305 could also contribute to a lower autolytic activity due to a reduced D-alanine esterification of the teichoic acids [37]. 
Table 3: Top scoring reporter metabolites ( $p$ - values $<0.05)$

\begin{tabular}{|c|c|c|c|c|}
\hline Metabolism $^{\mathrm{a}}$ & Metabolite & Number of neighbours & Z-score & $p$-value \\
\hline $\mathrm{A}, \mathrm{E}, \mathrm{N}$ & Carbamoyl phosphate & 5 & 4.341 & $<0.001$ \\
\hline $\mathrm{N}$ & N-Carbamoyl-L-aspartate & 2 & 2.878 & 0.002 \\
\hline $\mathrm{A}, \mathrm{E}, \mathrm{N}$ & Carbamate & 2 & 2.772 & 0.003 \\
\hline Co, $N$ & Uracil & 5 & 2.626 & 0.004 \\
\hline A & L-Citrulline & 3 & 2.484 & 0.006 \\
\hline$A$ & 4-Imidazolone-5-propanoate & 2 & 2.480 & 0.007 \\
\hline Co, $\mathrm{N}$ & Uracil (extracellular) & I & 2.210 & 0.014 \\
\hline $\mathrm{N}$ & Orotidine-5-phosphate & 2 & 2.182 & 0.015 \\
\hline C & Melibiose (extracellular) & I & 2.092 & 0.018 \\
\hline C & Raffinose (extracellular) & I & 2.092 & 0.018 \\
\hline A & N-Formimino-L-glutamate & 2 & 2.087 & 0.018 \\
\hline $\mathrm{L}$ & Trihexadecanoylglycerol & I & 2.075 & 0.019 \\
\hline A & L-Arginine (extracellular) & I & 2.075 & 0.019 \\
\hline A & L-Ornithine (extracellular) & I & 2.075 & 0.019 \\
\hline $\mathrm{L}$ & Phosphatidylethanolamine & 2 & 2.047 & 0.020 \\
\hline $\mathrm{L}$ & Phosphatidylcholine & 2 & 2.047 & 0.020 \\
\hline $\mathrm{L}$ & Choline phosphate & 2 & 2.047 & 0.020 \\
\hline $\mathrm{L}$ & Ethanolamine phosphate & 2 & 2.047 & 0.020 \\
\hline$A$ & 3-Methyl-2-oxopentanoate & 3 & 1.980 & 0.024 \\
\hline Co & Nicotinate & 2 & 1.979 & 0.024 \\
\hline C & Melibiose & 3 & 1.958 & 0.025 \\
\hline$A, C, L$ & Glycerol (extracellular) & I & 1.949 & 0.026 \\
\hline $\mathrm{N}$ & (S)-Dihydroorotate & 2 & 1.937 & 0.026 \\
\hline C, L & I,2-Dihexadecanoyl-sn-glycerol & 7 & 1.924 & 0.027 \\
\hline C & $\mathrm{N}$-Acetylneuraminate & I & 1.907 & 0.028 \\
\hline C & Itaconate & I & 1.884 & 0.030 \\
\hline C & Itaconyl-CoA & I & 1.884 & 0.030 \\
\hline C & Raffinose & 2 & 1.870 & 0.031 \\
\hline$A, C, N$ & D-Ribose & 2 & 1.860 & 0.031 \\
\hline A, C, L & Glycerol & 4 & 1.804 & 0.036 \\
\hline C, Co, N & Deoxyribose & I & 1.768 & 0.038 \\
\hline$A$ & 2-Aminoacrylate & I & 1.746 & 0.040 \\
\hline $\mathrm{A}, \mathrm{N}$ & GDP & 6 & 1.659 & 0.049 \\
\hline$N$ & Orotate & 2 & 1.659 & 0.049 \\
\hline $\mathrm{L}$ & (R)-5-Diphosphomevalonate & 2 & 1.650 & 0.049 \\
\hline
\end{tabular}

\footnotetext{
${ }^{a} \mathrm{~A}$, amino acid metabolism; C, carbohydrate metabolism; Co, metabolism of cofactors and vitamins; E, energy metabolism; L, lipid
} metabolism; $\mathrm{N}$, nucleotide metabolism

\section{Membrane and transporters}

One of the major components of the membrane, lysylphosphatidylglycerol, is a product of the lysylphosphatidylglycerol synthase FmtC (synonym: MprF), which adds a positively charged lysyl residue to phosphatidylglycerol $[38,39]$. The $f m t C / m p r F$ gene, which belongs to the socalled fem and aux genes, and the inactivation of which reduces methicillin and bacitracin resistance $[40,41]$, was found to be downregulated in BB1305. Reduced $\mathrm{fmtC}$ transcription may on the one hand mirror the reduced growth rate and could on the other hand, by its influence on the membrane charge, also be one of the causes for bacitracin and teicoplanin hypersusceptibility.
One fifth of the genes found differentially regulated in the fem $A B+$ backcross BB1305 code for membrane-associated proteins, mainly transporters and permeases, with the majority showing a reduced transcription level. Interestingly, opuCC, which encodes the substrate-binding protein of a glycine betaine/carnitine/choline ABC transporter, was upregulated as could be confirmed by Northern hybridization showing a stronger transcription of the whole opuC operon in BB1305 than in BB903 (data not shown). The uptake of compatible solutes such as glycine betaine, choline and proline is important in osmotic stress response [42,43], and the upregulation of $o p u C$ may indicate an attempt of the fem $A B$ deletion mutant to bal- 


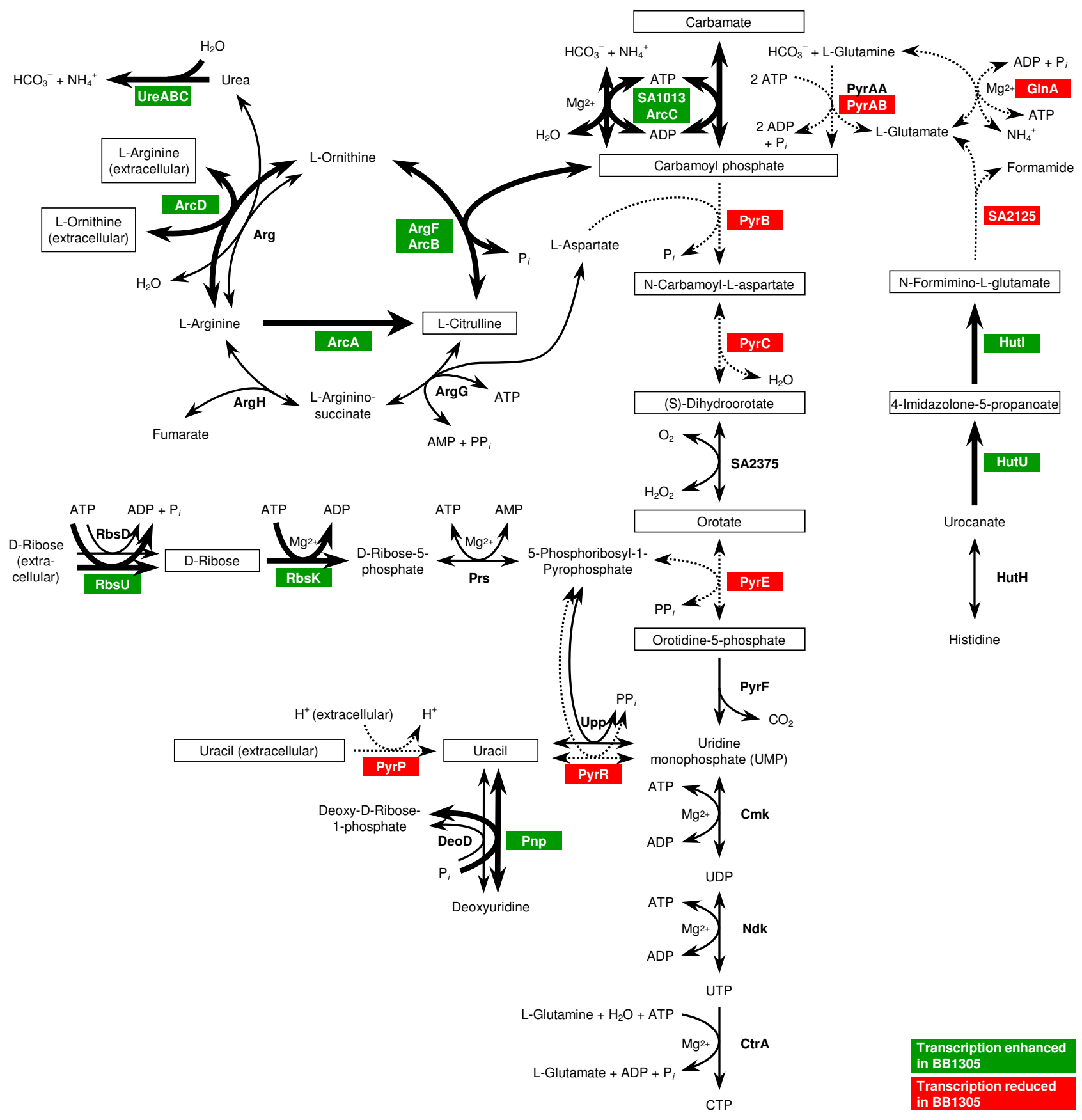

\section{Figure 6}

Metabolic pathways influenced by transcriptional changes observed in the femAB+ backcross $\mathrm{BB} / 305$. The corresponding gene ID numbers refer to the genome of $S$. aureus strain N3I5. Reactions driven by enzymes showing enhanced gene expression in BBI305 are marked with thick arrows, whereas those with reduced expression are indicated by dotted arrows. Reporter metabolites as ascertained by the method of Patil and Nielsen [67] are framed. 


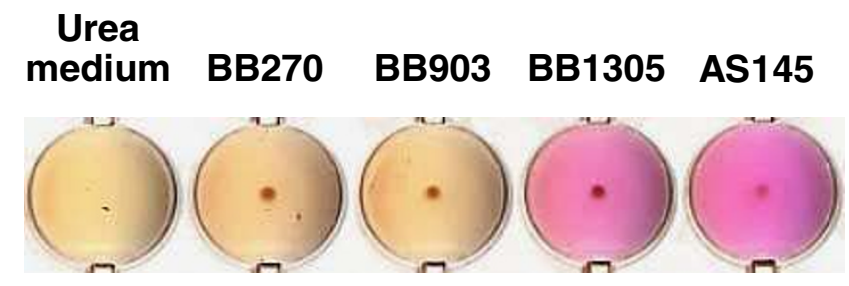

Figure 7

Urease production in urea-containing medium. The increase in $\mathrm{pH}$ resulting from the cleavage of urea is indicated by a purple colour.

ance osmotic pressure due to the weakened cell wall. In contrast, opuD and its homologue, sa1987, members of the betaine/carnitine/choline transporter (BCCT) family, were downregulated in BB1305. This latter family of transporters, however, may respond to other kinds of osmotic stress than the opuC operon.

Besides quaternary amines or amino acids, solutes such as polyols (e.g. glycerol, arabitol) and sugars (e.g. sucrose, trehalose) may play a role in osmoprotection [44]. Indeed, genes encoding transporters specific for these classes of compounds were also found to be upregulated in BB1305: namely the glycerol uptake facilitator $(g l p F)$, the sucrose-specific IIBC component of the phosphotransferase system (PTS) (scrA), and a hypothetical protein similar to ScrA (sa0186). Other genes encoding sugar transporters were also induced in BB1305, i.e. sa0208/ sa0209 (permease homologue of a maltose/maltodextrin $\mathrm{ABC}$ transporter), sa0260 (hypothetical protein similar to the ribose transporter RbsU), and sa0318/sa0320 (hypothetical protein similar to the pentitol-specific PTS transporter SgaT/SgaA). Considering the observed upregulation of $g l p F$, it is noteworthy that $g l p D$ (aerobic glycerol-3-phosphate dehydrogenase), glpQ (glycerophosphoryldiester phosphodiesterase), and sa0220 (hypothetical protein similar to GlpQ) also appeared to be upregulated in BB1305. These may support osmoprotection as GlpQ catalyzes the conversion of sn-glycero-3phosphocholine to glycerol-3-phosphate and choline, the latter of which is oxidized to glycine betaine, which is not metabolized further in osmotically stressed $S$. aureus [45].

\section{Stress response and virulence factors}

Given the temperature sensitivity of BB1305, a connection to the heat shock regulon was conceivable. In fact, the gene encoding the chaperone DnaK was downregulated according to the microarray data. DnaK belongs to the HrcA and CtsR controlled heat shock regulon in S. aureus
[46]. A dnaK-specific probe, revealed a $3.5 \mathrm{~kb}$-transcript in Northern blot analysis, most probably covering the hrcA operon, and confirmed reduced transcription levels in BB1305 at $37^{\circ} \mathrm{C}$ (data not shown).

Unfavourable environmental conditions are known to induce lysogenic phages, and the upregulation of phagerelated genes in BB1305 is most likely to be regarded in the context of a stress response which occurred in the fem $A B$ deletion mutant AS145. Various stress conditions have also been described to trigger the expression of virulence factors [21]. In BB1305, the transcriptional changes observed included the upregulation of a whole series of virulence genes, such as those coding for lipase (lip), urease (ure), $\alpha$-hemolysin precursor (sa1007), truncated $\beta$ hemolysin (sa1752 and sa1811), serine proteases (spl), cysteine protease $(s s p B)$ and aureolysin (aur). Since the expression of virulence factors depends on a complex regulatory network, this finding prompted us to analyze the transcription profiles of the major global regulators including sarA (staphylococcal accessory regulator), sae (S. aureus exoprotein expression) and the agr (accessory gene regulator) operon by Northern blot during growth. In accordance with the expression pattern of two representative virulence factors, namely the $\alpha$-hemolysin precursor (sa1007) and the serine proteases (splABCDEF), the regulators and especially RNAIII and saeRS peaked at a lower $\mathrm{OD}_{600}$ in the femAB+ backcross BB1305 than in BB903. At the transition to stationary phase, at an $\mathrm{OD}_{600}$ of 4 , they had already become clearly weaker in the mutant than in the wild type (Figure 8) revealing a remarkably altered timing in the transcription of the main global regulators in BB1305.

\section{Conclusion}

This is the first thorough characterization of compensatory effects triggered by a shortened pentaglycine interpeptide, the low ability of PBP to crosslink this altered peptidoglycan, and selection for survival. The poorly crosslinked cell wall may be not strong enough to withstand the cells' high internal turgor. This imbalance must have been sensed by the cells, which found a way to counteract osmotic stress, though at the cost of a decreased growth rate and temperature sensitivity. The rearrangements required also involved changes in the expression of metabolic pathways, especially of the arginine-deiminase pathway and the nitrogen metabolism, and seem to be maintained in a stable manner, since they persisted after restoration of the pentaglycine interpeptide. This demonstrates the vast extent of the compensatory adaptations. Such compensatory adaptations following mutagenesis may happen much more frequently than anticipated, and may be the cause of the often observed experimental inability to fully complement mutations with the original wild type alleles. 

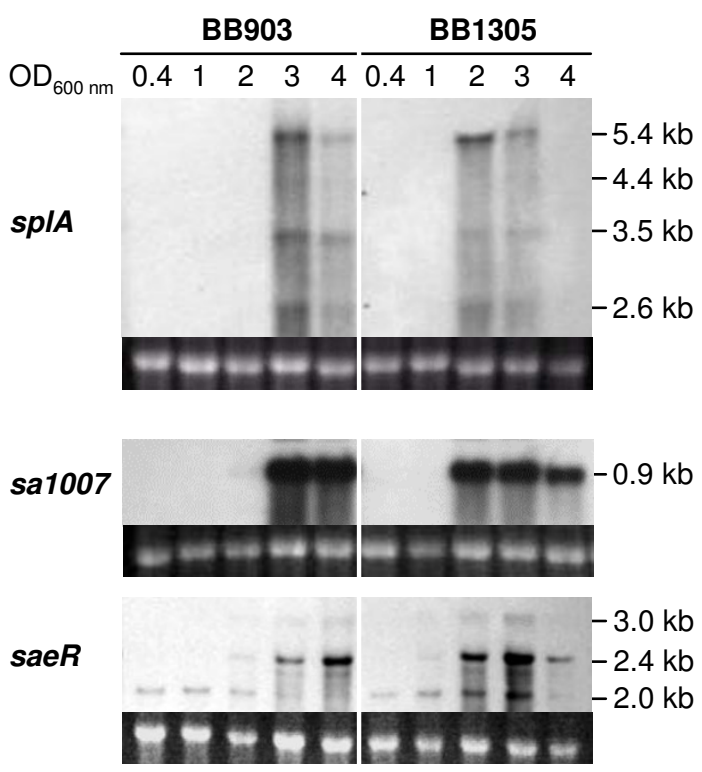

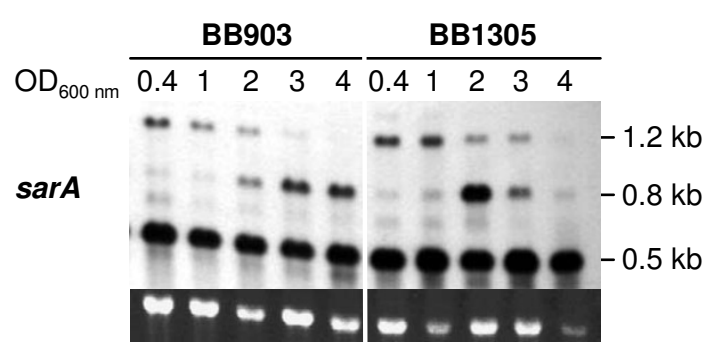

RNAII

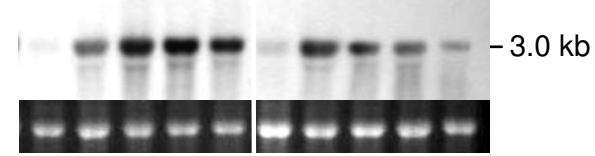

RNAIII

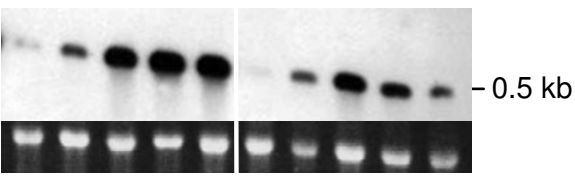

\section{Figure 8}

Northern blots of differentially expressed genes in the wild type BB903 and the femAB+ backcross BBI305. Cells were harvested at different optical densities as indicated. The amount of RNA loaded onto the respective gels is displayed by the ethidium bromide stained I6S rRNA bands.

Cell wall-deficient forms (L-forms) of $S$. aureus are able to survive without an intact murein sacculus, and to internalize and persist in macrophages [47]. Adaptive responses to L-forms of $S$. aureus have recently been described by Fuller et al. [48], who selected cell wall-deficient mutants with subinhibitory concentrations of penicillin in the presence of elevated osmolality. Similar to what we observed, namely that the reconstituted strain BB1305 displayed a higher, more homogeneous oxacillin resistance than the wild type, recovery of the cell wall by the Lforms resulted in a stably inherited penicillin resistance that was independent of a $\beta$-lactamase or mecA. Apparently, the expected negative effect of reduced $f m t C$ or $g \ln A$ expression on oxacillin resistance was compensated in BB1305. A phenomenon, that was also observed with other fem, aux or fmt MRSA mutants which still harboured their original mutations but regained resistance by compensatory events when grown in the presence of $\beta$-lactams $[18,49]$.

The temperature sensitivity and the increased susceptibility to bacitracin and teicoplanin are indications for permanent alterations in the membrane. Membrane defects may also be the cause for the premature upregulation of global regulators which in turn most probably triggered the enhanced expression of virulence factors [50,51].
It is likely that the adaptations represent just one of many ways that $S$. aureus could respond to $f e m A B$ inactivation. Some of the findings may be secondary effects caused by slow growth and changes within the cell, not contributing to survival, similar to the upregulation of the purine operon in vancomycin intermediate resistant $S$. aureus [52], that did not contribute to increased glycopeptide resistance [53].

At this stage, we cannot confirm that the numerous adaptive events that occurred in the $f e m A B$ deletion mutant and that are reflected in the fem $A B+$ cis-complemented strain were indeed due to mutation(s). The phenotypic adaptations revealed here, such as temperature sensitivity, slowed down growth, but no changes in autolytic activities, were strikingly similar to the phenotype caused by mutations in femA after selection for lysostaphin resistant clones [54], which might be evidence for a common survival strategy.

S. aureus has shown here a remarkable ability to compensate and survive a severe condition, such as fem $A B$ inactivation, which prevents peptidoglycan crosslinking. Implementation of potential Fem $A B$ inhibitors may therefore entail selection of resistant subpopulations having 
unwanted characteristics, making a combined treatment with other antibiotics highly advisable.

\section{Methods}

\section{Bacterial strains and growth conditions}

The strains used in this study are listed in Table 1. Bacteria were cultivated either on sheep blood agar or in Luria Bertani (LB) broth (Becton Dickinson, Sparks, MD) at $37^{\circ} \mathrm{C}$, unless stated otherwise. The ratio between broth and culture flask volume was $1: 5$ and incubation was carried out with shaking at $180 \mathrm{rpm}$.

\section{Scanning electron microscopy (SEM)}

Strains grown in brain heart infusion (BHI) broth at $30^{\circ} \mathrm{C}$ for $3 \mathrm{~h}$ were used to inoculate $1 \mathrm{ml}$ BHI broth in 24-well plates containing polyethylene terephthalate (Thermanox) disks (Life Technologies, Basel, Switzerland) to an $\mathrm{OD}_{600}$ of 0.05 . The cells were incubated in stationary culture at $30^{\circ} \mathrm{C}$ for $2 \mathrm{~h}$. Fixation and SEM were carried out as described previously [55].

\section{Peptidoglycan analysis}

Insoluble peptidoglycan was purified from cultures grown to mid-log phase in BHI broth using a standard procedure $[56,57]$. After removal of teichoic acids by hydrofluoric acid, the relative glycan chain lengths were determined in the peptidoglycan preparations as described elsewhere [58] and their muropeptide patterns were compared following digestion with muramidase [56].

\section{Antibiotic gradient plates}

Qualitative differences in resistance levels were evaluated by swabbing $0.5 \mathrm{McF}$ arland-standard cell suspensions, prepared from freshly grown overnight cultures, along an antibiotic gradient on rectangular LB agar plates. Gradient plates were incubated at $35^{\circ} \mathrm{C}$ for 24 to $48 \mathrm{~h}$.

\section{Population analysis profile}

Overnight cultures were diluted in $0.85 \% \mathrm{NaCl}$ and aliquots of $0.1 \mathrm{ml}$ were spread onto LB agar plates containing various oxacillin concentrations. Colony forming units (CFUs) were determined after $48 \mathrm{~h}$.

\section{Molecular biological methods}

General molecular biology techniques were performed as described by Sambrook et al. [59] and Ausubel et al. [60].

\section{Transcriptional profiling}

Overnight cultures were diluted 100-fold in LB broth and cells were grown to an $\mathrm{OD}_{600}$ of $0.8-1.0$. The cultures were stabilized by incubation with 2 volumes of RNAprotect Bacteria Reagent (QIAGEN, Hilden, Germany) for 5 min at room temperature. Subsequently, cells were harvested by centrifugation, lysed in the presence of $400 \mu \mathrm{g} / \mathrm{ml}$ lysostaphin (Sigma-Aldrich, Taufkirchen, Germany) and total RNA was isolated using the RNeasy Midi Kit (QIAGEN) following the manufacturers' instructions.

Three independent RNA preparations of each strain were reverse transcribed twice, using either cyanine-3' (Cy3) or cyanine-5' (Cy5) as a label. Briefly, $10 \mu \mathrm{g}$ of total RNA were transcribed into cDNA using Superscript II reverse transcriptase (Invitrogen, Karlsruhe, Germany). The transcription reaction was performed in the presence of 0.1 mM Cy3- or Cy5-labelled dCTP (Perkin Elmer Life Science, Mechelen, Belgium) in addition to $0.2 \mathrm{mM} \mathrm{dCTP,}$ $0.5 \mathrm{mM}$ dATP, dGTP and TTP, $75 \mu \mathrm{g} / \mathrm{ml}$ random hexamer primer (Amersham, Bioscience, Freiburg, Germany) and $4 \mathrm{U} / \mu \mathrm{l}$ RNase-Out (Invitrogen). RNA was degraded by alkaline hydrolysis at $65^{\circ} \mathrm{C}$ and cDNA was purified using the MinElute PCR Purification Kit (QIAGEN).

Differentially labelled cDNAs of both strains were competitively hybridized with a custom PCR product microarray (Scienion, Berlin, Germany) resulting in a total of six chips. The microarray contained 2332 open reading frames (ORFs) of the S.aureus N315 genome, each represented by adjacent duplicate spots. Hybridization was performed at $42^{\circ} \mathrm{C}$ for $72 \mathrm{~h}$ according to the manufacturer's instructions. The hybridized microarrays were read out with a GenePix 4000B scanner (Axon Instruments/Distribution by Biozyme, Oldendorf, Germany). Image analysis and acquisition of relative data were conducted using GenePixPro 4.1 software (Axon Instruments).

\section{Microarray data analysis}

First, the intensity data arising from the six two-colour spotted microarrays were calibrated and normalized in order to remove systematic technical variation (e.g. different labelling efficiencies and scanning properties of the Cy3 and Cy5 dyes) and to ensure that observed differences in intensities indeed reflect biological signal. Two-channel normalization was performed to adjust the centre and spread of the distribution of intensity log-ratios [61] using the default method of the "marray" package [62] in Bioconductor version 1.8 [63]. Adaptive location normalization within print-tip groups using robust local regression [64] allows the capture of non-linear dependencies of the intensity log-ratio on overall intensity, while ensuring that the computed normalization values are not driven by a small number of differentially expressed genes with extreme log-ratios. Due to scale differences between the arrays we also conducted global scale normalization across arrays.

For identification of differentially expressed genes between the femAB+ backcross BB1305 and the wild type BB903, the linear modelling features of the "limma" $\mathrm{R}$ package version 2.9.1 were used [65]. In the present experiment, three BB1305 RNA preparations were to be com- 
pared with three BB903 RNA preparations using six arrays, i.e. each RNA appeared on two different arrays. Note that technical replicates are not independent: in fact they are likely to be positively correlated. Since the experimental design did not arrange the arrays in groups of biological replicates, we fitted a model with a coefficient for each RNA preparation. The duplicate spots in adjacent position were taken into account by estimating a common value for the intra-duplicate correlation [66] that was used when fitting a linear model for each gene. Finally, we extracted the contrast referring to the average expression differences between the two investigated $S$. aureus strains and computed moderated $t$-statistics using empirical Bayes methods. These borrow information across genes and thus stabilize the analysis even for a small number of arrays [9]. The reported list of potentially interesting genes was determined by adjusting the $p$-values for multiple testing. Here we have chosen the FWER-based $p$-value adjustment according to Holm [10], where the multiple significance level $\alpha$ was set to 0.05 .

\section{Reporter metabolite analysis}

The microarray data were further analyzed by a recently developed algorithm that uses the topology of an organism's metabolic network to uncover underlying metabolism-related transcriptional regulation [67]. This algorithm first converts a genome-scale metabolic network of $S$. aureus N315 [11] into a bipartite metabolic graph. In this graph, each metabolite node is then scored based on the normalized transcriptional response of its neighbouring enzymes. Using the genes' $p$-values as inputs to score the enzyme nodes, the algorithm identifies so-called reporter metabolites, designating metabolites around which the most significant transcriptional changes occur.

\section{Northern blots}

The transcription of a selection of genes was verified by Northern hybridization and primers used for probe amplification are listed in Table 4. Overnight cultures were diluted 100-fold in LB broth and incubated for $2 \mathrm{~h}$. The pre-cultures were then diluted in LB broth to an $\mathrm{OD}_{600}$ of 0.05 and grown until they reached the desired $\mathrm{OD}_{600}$. Total RNA was extracted according to the method of Cheung et al. [68]. For Northern hybridization, $8 \mu \mathrm{g}$ of total RNA per sample were loaded on a $1.5 \%$ agarose gel containing $20 \mathrm{mM}$ guanidine thiocyanate in 1xTrisBorate-EDTA running buffer [69]. Blotting of the electrophoretically separated RNA and detection of transcripts were carried out as described earlier [70].

\section{Urease assay}

McFarland 0.5-standard cell suspensions were diluted 100 -fold in urea medium [71] and were incubated in 96well plates at $37^{\circ} \mathrm{C}$ for 24 hours.
Table 4: Primers used for construction of DIG-labelled DNA probes

\begin{tabular}{|c|c|}
\hline Primer & Sequence (5'-3') \\
\hline$d l t A-\mathrm{F}$ & TCAGGCGGTACATTAAATCTTGT \\
\hline dltA-R & TATGTGTTGTAAATCGTCGCACT \\
\hline dnaK-F & CGATGAGCCAAAAGTAATTC \\
\hline dnaK-R & TACTTCGAATACACCGTCAC \\
\hline$f m t C-F$ & CCGTATGTCCTTAGTGTTAC \\
\hline$f m t C-R$ & GCAGTACAATCCTACAAAAC \\
\hline$g \ln A-\mathrm{F}$ & AGATGGAACACCATTTGAAG \\
\hline$g \ln A-R$ & AAACGTTAAAGTGCATACCG \\
\hline$g \mid p F-F$ & TAGACGGAAGTTTTGATTGG \\
\hline$g / p F-R$ & GGCAATTGGTCCTAAGATAG \\
\hline opuCC-F & TTGTCGTGTTTGTCTTATCG \\
\hline opuCC-R & ACGTATTCGCAAAACCATAC \\
\hline pyrP-F & TTATCACGGGATTAAGTACG \\
\hline pyrP-R & ACAATCGGAATCATTACAAG \\
\hline pyrR-F & AACGTACAGTGACGAGAATC \\
\hline pyrR-R & TAACTGCATTTCTTTGATCC \\
\hline RNAll-F & CGAAGACGATCCAAAAC \\
\hline RNAll-R & TTATCTAAATGGGCAATGAGT \\
\hline RNAIII-F & GTGATGGAAAATAGTTGATGAG \\
\hline RNAIII-R & GTGAATTTGTTCACTGTGTCG \\
\hline sal007-F & TAATGAATCCTGTCGCTAAT \\
\hline sal007-R & TTCAGTGTATGACCAATCGAA \\
\hline saeR-F & GACCCACTTACTGATCGTG \\
\hline sae $R-R$ & ССТАATCCССАTACAGTTGTG \\
\hline sarA-F & AGGGAGGTTTTAAACATGGC \\
\hline sarA-R & CTCGACTCAATAATGATTCG \\
\hline splA-F & GAATTACCTGGTTGTGCATACG \\
\hline splA-R & GAAGACCTTGCGATAGTTCATG \\
\hline
\end{tabular}

\section{Authors' contributions}

$\mathrm{JH}$ carried out phenotypic characterizations and Northern blots, experimentally validated the microarray data, contributed to the interpretation of the results, and drafted the manuscript. AJ carried out the microarrays. OK performed the reporter metabolite analysis. JS performed the statistical analyses. PAM conducted the peptidoglycan analyses. LGH carried out the scanning electron microscopy. GB participated in the design of the microarray experiments and their interpretation. $\mathrm{MH}$ supervised the reporter metabolite analysis and interpreted its results. BBB conceived, designed, and coordinated the study, and participated in writing of the manuscript. All authors read and approved the final manuscript. 


\section{Additional material}

\section{Additional file 1}

Genes found differentially expressed in the fem $\mathrm{AB}+$ backcross BB1305 compared to the wild type BB903. The selection of regulated genes is based on statistical significance of moderated $\mathrm{t}$-scores and thus also includes genes with a $\log _{2}($ fold change $)<|1|$. The genes are clustered according to their cellular main role as in the S. aureus N315 genome annotation on the DOGAN website [73].

Click here for file

[http://www.biomedcentral.com/content/supplementary/1471-

2164-8-307-S1.pdf]

\section{Acknowledgements}

This study was supported by LSHM-CT-2003-503335 (SBF03.0098) and Swiss National Science Foundation grant 31-105390/I to B.B.-B., a grant of the Federal Ministry of Education and Research of Germany (Pathogenomics, PTJ-BIO/03U2 I3B, 60 I I I-4/I - V II ZV -03, V I PG I) to G.B., Swiss National Science Foundation grant 3200B0-103793 to P.A.M., and financial support from DSM Nutritional Products to J.S.

\section{References}

I. Maidhof $H$, Reinicke B, Blümel P, Berger-Bächi B, Labischinski H: femA, which encodes a factor essential for expression of methicillin resistance, affects glycine content of peptidoglycan in methicillin-resistant and methicillin-susceptible Staphylococcus aureus strains. J Bacteriol I991, 173:3507-35 I3.

2. Strandén AM, Ehlert K, Labischinski H, Berger-Bächi B: Cell wall monoglycine cross-bridges and methicillin hypersusceptibility in a femAB null mutant of methicillin-resistant Staphylococcus aureus. J Bacteriol 1997, 179:9-16.

3. Rohrer S, Ehlert K, Tschierske M, Labischinski H, Berger-Bächi B: The essential Staphylococcus aureus gene $\mathrm{fmhB}$ is involved in the first step of peptidoglycan pentaglycine interpeptide formation. Proc Natl Acad Sci USA 1999, 96:935I-9356.

4. Schneider T, Senn MM, Berger-Bächi B, Tossi A, Sahl HG, Wiedemann I: In vitro assembly of a complete, pentaglycine interpeptide bridge containing cell wall precursor (lipid II-Gly5) of Staphylococcus aureus. Mol Microbiol 2004, 53:675-685.

5. Ehlert K, Schroder W, Labischinski H: Specificities of FemA and FemB for different glycine residues: FemB cannot substitute for FemA in staphylococcal peptidoglycan pentaglycine side chain formation. J Bacteriol 1997, 1 79:7573-7576.

6. Ling BD, Berger-Bächi B: Increased overall antibiotic susceptibility in Staphylococcus aureus femAB null mutants. Antimicrob Agents Chemother 1998, 42:936-938.

7. Tschierske M, Mori C, Rohrer S, Ehlert K, Shaw KJ, Berger-Bächi B: Identification of three additional femAB-like open reading frames in Staphylococcus aureus. FEMS Microbiol Lett 1999, 171:97-102.

8. Beauregard DA, Williams DH, Gwynn MN, Knowles DJ: Dimerization and membrane anchors in extracellular targeting of vancomycin group antibiotics. Antimicrob Agents Chemother 1995, 39:78I-785.

9. Smyth GK: Linear models and empirical Bayes methods for assessing differential expression in microarray experiments. Stat Appl Genet Mol Biol 2004, 3:Article 3.

10. Holm S: A simple sequentially rejective multiple test procedure. Scand J Statist 1979, 6:65-70.

II. Heinemann M, Kummel A, Ruinatscha R, Panke S: In silico genomescale reconstruction and validation of the Staphylococcus aureus metabolic network. Biotechnol Bioeng 2005, 92:850-864.

12. Kohler C, von Eiff C, Peters G, Proctor RA, Hecker M, Engelmann S: Physiological characterization of a heme-deficient mutant of Staphylococcus aureus by a proteomic approach. J Bacteriol 2003, I 85:6928-6937.
13. Seggewiss J, Becker K, Kotte O, Eisenacher M, Yazdi MR, Fischer A, McNamara P, Al Laham N, Proctor R, Peters G, Heinemann M, von Eiff C: Reporter metabolite analysis of transcriptional profiles of a Staphylococcus aureus strain with normal phenotype and its isogenic hemB mutant displaying the small-colony-variant phenotype. J Bacteriol 2006, I 88:7765-7777.

14. Beenken KE, Dunman PM, McAleese F, Macapagal D, Murphy E, Projan SJ, Blevins JS, Smeltzer MS: Global gene expression in Staphylococcus aureus biofilms. J Bacteriol 2004, I 86:4665-4684.

15. Resch A, Rosenstein R, Nerz C, Götz F: Differential gene expression profiling of Staphylococcus aureus cultivated under biofilm and planktonic conditions. Appl Environ Microbiol 2005, 7I:2663-2676.

16. Yao Y, Sturdevant DE, Otto M: Genome-wide analysis of gene expression in Staphylococcus epidermidis biofilms: insights into the pathophysiology of $S$. epidermidis biofilms and the role of phenol-soluble modulins in formation of biofilms. J Infect Dis 2005, 1 91 :289-298.

17. Diep BA, Gill SR, Chang RF, Phan TH, Chen JH, Davidson MG, Lin F, Lin J, Carleton HA, Mongodin EF, Sensabaugh GF, Perdreau-Remington $F$ : Complete genome sequence of USA300, an epidemic clone of community-acquired meticillin-resistant Staphylococcus aureus. Lancet 2006, 367:731-739.

18. Gustafson J, Strässle A, Hächler H, Kayser FH, Berger-Bächi B: The femC locus of Staphylococcus aureus required for methicillin resistance includes the glutamine synthetase operon. J Bacteriol 1994, I76: I460-I 467

19. Atkinson MR, Fisher SH: Identification of genes and gene products whose expression is activated during nitrogen-limited growth in Bacillus subtilis. J Bacteriol 1991, 173:23-27.

20. Wray LV Jr, Ferson AE, Fisher SH: Expression of the Bacillus subtilis ureABC operon is controlled by multiple regulatory factors including CodY, GInR, TnrA, and Spo0H. J Bacteriol I997, I 79:5494-550I.

21. Anderson KL, Roberts C, Disz T, Vonstein V, Hwang K, Overbeek R, Olson PD, Projan S], Dunman PM: Characterization of the Staphylococcus aureus heat shock, cold shock, stringent, and SOS responses and their effects on log-phase mRNA turnover. J Bacteriol 2006, I 88:6739-6756.

22. Turner RJ, Lu Y, Switzer RL: Regulation of the Bacillus subtilis pyrimidine biosynthetic (pyr) gene cluster by an autogenous transcriptional attenuation mechanism. J Bacteriol 1994, 176:3708-3722

23. Lu Y, Switzer RL: Transcriptional attenuation of the Bacillus subtilis pyr operon by the PyrR regulatory protein and uridine nucleotides in vitro. J Bacteriol 1996, I78:7206-72।I.

24. Bonner ER, D'Elia JN, Billips BK, Switzer RL: Molecular recognition of pyr mRNA by the Bacillus subtilis attenuation regulatory protein PyrR. Nucleic Acids Res 200 I, 29:485I-4865.

25. Richardson AR, Dunman PM, Fang FC: The nitrosative stress response of Staphylococcus aureus is required for resistance to innate immunity. Mol Microbiol 2006, 61 :927-939.

26. Schreier HJ, Brown SW, Hirschi KD, Nomellini JF, Sonenshein AL: Regulation of Bacillus subtilis glutamine synthetase gene expression by the product of the gInR gene. J Mol Biol 1989, $210: 51-63$.

27. Wray LV Jr, Ferson AE, Rohrer K, Fisher SH: TnrA, a transcription factor required for global nitrogen regulation in Bacillus subtilis. Proc Natl Acad Sci USA 1996, 93:884I-8845.

28. Schreier HJ, Caruso SM, Maier KC: Control of Bacillus subtilis glutamine synthetase expression by gInR from Staphylococcus aureus. Curr Microbiol 2000, 41:425-429.

29. Doroshchuk NA, Gel'fand MS, Rodionov DA: [Regulation of nitrogen metabolism in gram-positive bacteria]. Mol Biol (Mosk) 2006, 40:919-926.

30. Gutowski JC, Schreier HJ: Interaction of the Bacillus subtilis gInRA repressor with operator and promoter sequences in vivo. J Bacteriol 1992, I 74:67|-68I.

31. Schreier HJ, Rostkowski CA, Nomellini JF, Hirschi KD: Identification of DNA sequences involved in regulating Bacillus subtilis gInRA expression by the nitrogen source. J Mol Biol 1991, 220:24I-253

32. Murakami K, Fujimura T, Doi M: Nucleotide sequence of the structural gene for the penicillin-binding protein 2 of Staphylococcus aureus and the presence of a homologous gene in other staphylococci. FEMS Microbiol Lett 1994, I I7:131-136. 
33. Park W, Matsuhashi M: Staphylococcus aureus and Micrococcus luteus peptidoglycan transglycosylases that are not penicillin-binding proteins. J Bacteriol 1984, I 57:538-544.

34. Terrak $M$, Nguyen-Distèche $M$ : Kinetic characterization of the monofunctional glycosyltransferase from Staphylococcus aureus. I Bacteriol 2006, I 88:2528-2532.

35. Jolliffe LK, Doyle RJ, Streips UN: Extracellular proteases modify cell wall turnover in Bacillus subtilis. I Bacteriol 1980, | 41: I | 99- I 208.

36. Rice K, Peralta R, Bast D, de Azavedo J, McGavin MJ: Description of staphylococcus serine protease (ssp) operon in Staphylococcus aureus and nonpolar inactivation of sspA-encoded serine protease. Infect Immun 200I, 69:159-169.

37. Peschel A, Otto M, Jack RW, Kalbacher H, Jung G, Götz F: Inactivation of the dlt operon in Staphylococcus aureus confers sensitivity to defensins, protegrins, and other antimicrobial peptides. J Biol Chem 1999, 274():8405-84I0.

38. Peschel A, Jack RW, Otto M, Collins LV, Staubitz P, Nicholson G, Kalbacher $H$, Nieuwenhuizen WF, Jung G, Tarkowski A, van Kessel KP, van Strijp JA: Staphylococcus aureus resistance to human defensins and evasion of neutrophil killing via the novel virulence factor MprF is based on modification of membrane lipids with L-lysine. J Exp Med 200I, I 93: I067-1076.

39. Staubitz P, Neumann H, Schneider T, Wiedemann I, Peschel A: MprFmediated biosynthesis of lysylphosphatidylglycerol, an important determinant in staphylococcal defensin resist ance. FEMS Microbiol Lett 2004, 23 I:67-71.

40. Komatsuzawa $H$, Ohta K, Fujiwara T, Choi GH, Labischinski H, Sugai $\mathrm{M}$ : Cloning and sequencing of the gene, fmtC, which affects oxacillin resistance in methicillin-resistant Staphylococcus aureus. FEMS Microbiol Lett 200I, 203:49-54.

41. Nishi $H$, Komatsuzawa $H$, Fujiwara T, McCallum N, Sugai $M$ : Reduced content of lysyl-phosphatidylglycerol in the cytoplasmic membrane affects susceptibility to moenomycin, as well as vancomycin, gentamicin, and antimicrobial peptides, in Staphylococcus aureus. Antimicrob Agents Chemother 2004, 48:4800-4807.

42. Miller KJ, Zelt SC, Bae JH: Glycine betaine and proline are the principal compatible solutes of Staphylococcus aureus. Curr Microbiol 1991, 23:131-137.

43. Graham JE, Wilkinson BJ: Staphylococcus aureus osmoregulation: roles for choline, glycine betaine, proline, and taurine. J Bacteriol | 992, | 74:27| |-27|6.

44. Oren A: Bioenergetic aspects of halophilism. Microbiol Mol Biol Rev 1999, 63:334-348.

45. Kaenjak A, Graham JE, Wilkinson BJ: Choline transport activity in Staphylococcus aureus induced by osmotic stress and low phosphate concentrations. I Bacteriol 1993, I 75:2400-2406.

46. Chastanet A, Fert J, Msadek T: Comparative genomics reveal novel heat shock regulatory mechanisms in Staphylococcus aureus and other Gram-positive bacteria. Mol Microbiol 2003 47:106I-1073.

47. Michailova L, Kussovsky V, Radoucheva T, Jordanova M, Markova N Persistence of Staphylococcus aureus L-form during experimental lung infection in rats. FEMS Microbiol Lett 2007 268:88-97.

48. Fuller E, Elmer C, Nattress F, Ellis R, Horne G, Cook P, Fawcett T: Beta-lactam resistance in Staphylococcus aureus cells that do not require a cell wall for integrity. Antimicrob Agents Chemother 2005, 49:5075-5080.

49. Glanzmann P, Gustafson J, Komatsuzawa H, Ohta K, Berger-Bächi B: glmM operon and methicillin-resistant glmM suppressor mutants in Staphylococcus aureus. Antimicrob Agents Chemother 1999, 43:240-245.

50. Cheung AL, Bayer AS, Zhang G, Gresham H, Xiong YQ: Regulation of virulence determinants in vitro and in vivo in Staphylococcus aureus. FEMS Immunol Med Microbiol 2004, 40:I-9.

51. Rogasch K, Ruhmling V, Pane-Farre J, Hoper D, Weinberg C, Fuchs S, Schmudde M, Broker BM, Wolz C, Hecker M, Engelmann S: Influence of the two-component system SaeRS on global gene expression in two different Staphylococcus aureus strains. J Bacteriol 2006, I 88:7742-7758.

52. Mongodin E, Finan J, Climo MW, Rosato A, Gill S, Archer GL: Microarray transcription analysis of clinical Staphylococcus aureus isolates resistant to vancomycin. I Bacteriol 2003 185:4638-4643.
53. Fox PM, Climo MW, Archer GL: The lack of relationship between purine biosynthesis and vancomycin resistance in Staphylococcus aureus: a cautionary tale for microarray interpretation. Antimicrob Agents Chemother 2007, 5 I : | 274- | 280.

54. Kusuma C, Jadanova A, Chanturiya T, Kokai-Kun JF: Lysostaphin resistant variants of Staphylococcus aureus demonstrate reduced fitness in vitro and in vivo. Antimicrob Agents Chemother 2007, 5 I:475-482

55. Harris LG, Tosatti S, Wieland M, Textor M, Richards RG: Staphylococcus aureus adhesion to titanium oxide surfaces coated with non-functionalized and peptide-functionalized poly(Llysine)-grafted-poly(ethylene glycol) copolymers. Biomaterials 2004, 25:4|35-4|48.

56. de Jonge BL, Chang YS, Gage D, Tomasz A: Peptidoglycan composition of a highly methicillin-resistant Staphylococcus aureus strain. The role of penicillin binding protein 2A. J Biol Chem 1992, 267: I | 248-I I 254.

57. Majcherczyk PA, Rubli E, Heumann D, Glauser MP, Moreillon P: Teichoic acids are not required for Streptococcus pneumoniae and Staphylococcus aureus cell walls to trigger the release of tumor necrosis factor by peripheral blood monocytes. Infect Immun 2003, 7 I:3707-37I3.

58. Bischoff $M$, Roos $M$, Putnik J, Wada A, Glanzmann P, Giachino $P$ Vaudaux $P$, Berger-Bächi $B$ : Involvement of multiple genetic loci in Staphylococcus aureus teicoplanin resistance. FEMS Microbiol Lett 200I, 194:77-82.

59. Sambrook J, Fritsch EF, Maniatis T: Molecular cloning: A laboratory manual. Cold Spring Harbor, Cold Spring Harbor Laboratory Press; 1989.

60. Ausubel FM, Brent R, Kingston RE, Moore DD, Seidman JG, Smith JA, Struhl K: Current protocols in molecular biology. New York, John Wiley and Sons, Inc; 1987.

61. Yang YH, Dudoit S, Luu P, Lin DM, Peng V, Ngai J, Speed TP: Normalization for cDNA microarray data: a robust composite method addressing single and multiple slide systematic variation. Nucleic Acids Res 2002, 30:e I5.

62. Dudoit S, Yang YH: Bioconductor $\mathbf{R}$ packages for exploratory analysis and normalization of cDNA microarray data. In The Analysis of Gene Expression Data: Methods and Software Edited by: Parmigiani G, Garrett ES, Irizarry RA and Zeger SL. New York, Springer; 2003:73-101.

63. Bioconductor [http://www.bioconductor.org/]

64. Cleveland WS: Robust locally weighted regression and smoothing scatterplots. J Am Stat Assoc 1979, 74(368):829-836.

65. Smyth GK. Limma: linear models for microarray data. In Bioinformatics and Computational Biology Solutions using $R$ and Bioconductor Edited by: Gentleman R, Carey V, Dudoit S, Irizarry RA and Huber W. New York, Springer; 2005:397-420.

66. Smyth GK, Michaud J, Scott HS: Use of within-array replicate spots for assessing differential expression in microarray experiments. Bioinformatics 2005, 2 I :2067-2075.

67. Patil KR, Nielsen J: Uncovering transcriptional regulation of metabolism by using metabolic network topology. Proc Natl Acad Sci USA 2005, 1 02:2685-2689.

68. Cheung AL, Eberhardt $\mathrm{KJ}$, Fischetti VA: A method to isolate RNA from gram-positive bacteria and mycobacteria. Anal Biochem 1994, 222:5I|-514

69. Goda SK, Minton NP: A simple procedure for gel electrophoresis and northern blotting of RNA. Nucleic Acids Res 1995 , 23:3357-3358.

70. McCallum N, Bischoff M, Maki H, Wada A, Berger-Bächi B: TcaR, a putative MarR-like regulator of sarS expression. I Bacteriol 2004, I 86:2966-2972.

7I. Christensen WB: Urea decomposition as a means of differentiating Proteus and paracolon cultures from each other and from Salmonella and Shigella types. J Bacteriol 1946, 52:46 I-466.

72. Berger-Bächi B: Insertional inactivation of staphylococcal methicillin resistance by Tn55 I. J Bacteriol I 983, I 54:479-487.

73. Database Of the Genomes Analyzed at NITE (DOGAN) [http://www.bio.nite.go.jp/dogan/MicroTop?GENOME ID=n3|5] 